\title{
EDUCAÇÃO SEXUAL E RELAÇÕES DE GÊNERO: ONDE/COMO A BIOLOGIA SE COLOCA NESSA DISCUSSÃO?*
}

Jimena Furlani

\section{A Biologia em posição paradoxal}

Quando fui aprovada no Concurso Público para UDESC, no ano de 1994, para as disciplinas Biologia Educacional (I e II), que ocupavam naquela Matriz Curricular a 1a. e a 2a. fases do Curso de Pedagogia, eu não pensava em ser educadora sexual. Ao assumir minhas atividades docentes na UDESC, eu imediatamente fui convidada, e comecei a participar, do NES Núcleo de Estudos da Sexualidade ${ }^{1}$. Como o NES realizava reuniões sistemáticas de estudos e discussão de temas diversos da sexualidade humana (sempre voltados ao processo ensino-aprendizado e à formação de crianças, jovens e adultos), eu comecei a perceber que as Ciências Biológicas ocupavam estratégico papel no debate: primeiro, como importante, e sempre presente, campo do conhecimento científico trazido para explicar a maioria das perguntas; segundo, como o primeiro campo do conhecimento científico a ser questionado quando se pretendia, que o entendimento das Ciências Humanas e Sociais superassem (ou fossem considerados mais importantes) para explicar, para se entender e para definir uma prática de Educação Sexual, de reconhecimento da diversidade, no processo da escolarização formal.

Como Bióloga, eu aceitei o desafio de me tornar uma educadora sexual e, logo percebi nas conversas que a Biologia assumia um papel paradoxal. Ao mesmo tempo em que era fundamental para muitas das discussões e interesses das crianças e jovens, ela era, também, o campo do conhecimento usado para fixar entendimentos que reforçavam o preconceito, em especial, o ponto de vista que a sexualidade humana deve ser justificada,

${ }^{*}$ DOI - 10.29388/978-65-86678-66-6-f.91-110

${ }^{1}$ NES - Núcleo de Estudos da Sexualidade, um núcleo temático de Extensão Universitária, criado na FAED em 1991, pelas docentes Maria da Graça Soares e Sônia Maria Martins de Melo, como ação de extensão universitária. Quando ingressei no NES, em 1994, além das professoras Maria da Graça Soares e Sônia Maria Martins de Melo, também participaram, entre outras, a professora Celina Cordioli, as técnicas-universitária Rosi Pocovi e Lorieti Maria Nardelli da Luz e a acadêmica Júlia Siqueira da Rocha. 
apenas, pelo objetivo da reprodução e que a única orientação sexual aceitável é a heterossexualidade (aspectos estes que retornarei na discussão sobre o Determinismo Biológico).

Dito isso, podemos voltar a pergunta inicial, título desse artigo: Educação Sexual e Relações de Gênero: onde/como a Biologia se coloca nessa discussão ${ }^{2}$ Entendo que o nosso papel (de biólogas e biólogos, professoras e professores de Ciências da Natureza e de Biologia) vai além da transmissão dos conhecimentos sistematizados acerca do nosso campo científico. É também, o de refletir e o de questionar os usos argumentativos e explicativos que têm sido feitos, por aqueles que se apropriam da Biologia para reforçar preconceitos e discriminações. E para isso, destaco as seguintes "linhas de frente" que no meu entendimento definem o modo como a Biologia pode atuar: a) questionando o Determinismo Biológico; b) reforçando o Letramento Científico; e c) aproximando-se das Ciências Humanas e Sociais.

\section{a) Questionando o Determinismo Biológico}

Não foi sem propósito que Simone de Beauvoir (1908-1986), em 1949, na obra em que afirmou "não se nasce mulher, torna-se", intitulou seu Capítulo 1, de "os dados da Biologia" (Primeiro Volume: 1. Fatos e Mitos; Primeira Parte: Destino). Após longa e densa explanação sobre aspectos embriológicos, fisiológicos, endócrinos e reprodutivos, que distinguem homens e mulheres, ela afirmou:

Esses dados biológicos são de extrema importância [...] eis porque os estudamos tão demoradamente; são chaves que permitem compreender a mulher. Mas, o que recusamos, é a ideia de que constituem um destino imutável para ela. Não bastam para definir uma hierarquia dos sexos; não explicam por que a mulher é o Outro; não a condenam a conservar para sempre essa condição subordinada. (BEAUVOIR, 2002, p.52) (grifos meus)

\footnotetext{
${ }^{2}$ A convite do Prof. Dr. Emerson Luiz Gumboski, no dia 03/09/2020, como atividade integrante da XXVI Semana do Biólogo, da UNIVILLE - Joinville/SC, realizei a live intitulada Sexualidade e Estudos de Gênero na Escola: como a Biologia se coloca nessa discussão? Apresentarei, neste artigo, alguns entendimentos discutidos naquela oportunidade.
} 
Simone de Beauvoir (2002) questionará o fato de ser a mulher um ser humano de "segunda categoria". Isso a fez intitular sua obra de "O Segundo Sexo" - como ela afirma: "a mulher é o Outro" (p.52). Para ela, os dados da Biologia, para serem percebidos em suas implicações, precisam ser contextualizados à luz dos aspectos ontológico, econômico, social e psicológico (Beauvoir, 2002, p.57). Após afirmar que o corpo da mulher, embora essencial, não basta para defini-la, conclui: "A biologia não basta para fornecer uma resposta à pergunta: por que a mulher é o Outro? Trata-se de saber como a natureza foi nela revista através da história; trata-se de saber o que a humanidade fez da fêmea humana" (p.57) (grifos meus).

Embora ainda não usasse a categoria "gênero" (que passaria a ser utilizada pelos Estudos de Mulheres e pelos Feminismos, somente a partir dos anos de 1960-1970), Simone de Beauvoir já entendia as construções sociais, culturais e históricas como definidoras dos significados que hierarquizavam os sexos (mulheres e homens) - e, são essas construções sociais e culturais que respondem a pergunta "o que a humanidade fez da fêmea humana".

Se utilizar das diferenças biológicas para posicionar hierarquicamente ou qualificar mulheres e homens na sociedade (determinando o estilo de vida ou aquilo que lhes deve ser próprio), é o que denominamos de DETERMINISMO BIOLóGICO. Ou seja, quando a Biologia é usada como parâmetro para se determinar o que é aceitável, socialmente, para mulheres e homens, ou, quando é a partir da Biologia que se significa o que é considerado normal - mesmo que essa determinação seja arbitrária, estamos presenciando o Determinismo Biológico atuar.

Dito de outra forma: Determinismo Biológico é quando a Biologia é usada como o critério da normalidade; quando a Biologia é usada como o único aspecto que justifica o comportamento definido como natural. E, esse conjunto de significados sociais é o que, as Ciências Humanas e Sociais, a partir dos anos de 1960-1970, nos dirá que são as muitas representações, os significados construídos acerca das relações de gênero.

Para Londa Schiebinger (2001) contestar a Biologia foi fundamental ao Feminismo da Diferença e, tal crítica, impulsionou o surgimento do termo gênero.

O termo "gênero" foi introduzido na década de 1970 em tentativas de refrear o então avassalador determinismo biológico, no sentido de distinguir, formas culturalmente específicas de masculinidade e fe- 
minilidade, de "sexo" biológico (construído como cromossomos, fisiologia e anatomia) (SCHIEBINGER, 2002, p.45)

A seguir, apresentarei três exemplos de significados sociais (construções de gênero) que foram/são construídos nas sociedades, ao longo da história, a partir de fatos biológicos, ou seja, dentro da lógica estabelecida pelo Determinismo Biológico. Os significados socioculturais são o que denominamos construções de gênero e definem, ou tem definido, para muitas pessoas, não apenas o comportamento social esperado, mas também, como deve ser a educação de meninos e meninas/homens e mulheres.

Exemplo 1: Quando a capacidade de gerar determina a posição social das mulheres

\begin{tabular}{|l|l|}
\hline $\begin{array}{l}\text { A Biologia } \\
\text { OS FATOS BIOLÓGICOS }\end{array}$ & $\begin{array}{l}\text { Construçães de Gênero } \\
\text { OS SIGNIFICADOS SOCIOCULTURAIS e seus } \\
\text { enunciados }\end{array}$ \\
\hline $\begin{array}{l}\text { 1. Na espécie humana são as fê- } \\
\text { meas que engravidam. }\end{array}$ & $\begin{array}{l}\text { A maternidade (ser mãe) é o grande sonho de } \\
\text { toda mulher. } \\
\text { Uma mulher que não é mãe não pode "ser rea- } \\
\text { lizada". } \\
\text { As mulheres são mais frágeis, sensíveis e inde- } \\
\text { fesas. } \\
\text { As mulheres devem ocupar o espaço domésti- } \\
\text { co luz lo lar. } \\
\text { Ser mãe ou ser pai é desejo de casais heteros- } \\
\text { sexuais. } \\
\text { Toda família deve ser constituída de filhos/as. }\end{array}$ \\
\hline
\end{tabular}

Para os Estudos das Relações de Gênero são legítimas expressões da sexualidade: a maternidade, a mulher que escolhe viver para o lar se dedicando ao marido e filhos/filhas, a família heterossexual, a prole numerosa etc. No entanto, a crítica feita ao Determinismo Biológico está no seu caráter de compulsoriedade (de única possibilidade, de imposição, de destino) e de qualificar, esses estilos de vida, como os únicos legítimos, aceitáveis e "normais" àquelas mulheres que pretendessem ter valor e reconhecimento social. Da mesma forma, as conclusões decorrentes desse Determinismo Biológico impõem um modelo de masculinidade distante dos cuidados das fiIhas/filhos e da responsabilidade com a paternidade - modelo esse que será questionado na educação dos meninos, desde a Educação Infantil, pela 
Pedagogia e pela formação inicial e continuada de professoras/res para a Educação Básica.

Exemplo 2: Quando a testosterona normaliza a violência nos homens

\begin{tabular}{|l|l|}
\hline $\begin{array}{l}\text { A Biologia } \\
\text { OS FATOS BIOLÓGICOS }\end{array}$ & $\begin{array}{l}\text { Construções de Gênero } \\
\text { OS SIGNIFICADOS SOCIOCULTURAIS e seus enun- } \\
\text { ciados }\end{array}$ \\
\hline $\begin{array}{l}\text { 1. Os machos mamíferos } \\
\text { produzem o hormônio tes- } \\
\text { tosterona. }\end{array}$ & $\begin{array}{l}\text { O desejo sexual nos homens é incontrolável o } \\
\text { que justifica a necessidade de trair. } \\
\text { O homem tem mais necessidade de sexo do que } \\
\text { a mulher. } \\
\text { Homem que é homem não leva desaforo para } \\
\text { 2. A testosterona está relaci- } \\
\text { onada com a libido (desejo } \\
\text { sexual) e com a agressivida- } \\
\text { de, nos homens. }\end{array}$ \\
$\begin{array}{l}\text { casa. } \\
\text { A violência nos homens é natural e esperada. } \\
\text { A violência nos meninos e homens deve ser in- } \\
\text { centivada para que não se tornem homossexuais. } \\
\text { Mostrar-se violento é sinal de ser heterossexual. }\end{array}$ \\
\hline
\end{tabular}

Em 2016, a BBC Brasil publicou o artigo "Por que os homens são responsáveis por 95\% dos homicídios do mundo?" (RODRIGUES, Margarita, 2016) ${ }^{3}$. Segundo a pesquisa, as causas da violência apontavam para: o consumo de álcool; o acesso às armas de fogo; a tendência masculina a participar de quadrilhas e atividades do crime organizado e, aos papéis do homem e da mulher em certas sociedades (grifos meus).

Se a "tendência masculina" pode ser explicada pela Biologia (presença da testosterona nos homens), os "papéis definidos em cada sociedade" remetem ao conceito das relações de gênero e expressam o caráter da educação, dos processos de socialização envolvidos no aprendizado da violência. Para quem realiza Educação Sexual na escola e tem os Estudos das Relações de Gênero como referencial teórico, é o aspecto educacional que nos interessa (mais, do que o efeito da Biologia nos corpos das crianças e jovens). Não porque a Biologia não seja importante, mas, porque é a educação que está ao nosso alcance de mudança, como um processo de forma-

\footnotetext{
${ }^{3}$ Nessa reportagem profissionais, de diferentes campos (que se utilizam dos Estudos das Relações de Gênero em suas análises) se manifestam reforçando a importância dos processos de socialização no aprendizado da violência: Caronl Gentry, professora da Universidade de St Andrews (Escócia) e especialista em terrorismo e gênero; Lawrence Sherman, Diretor do Instituto de Criminologia da Universidade de Cambridge; Jocelyn Viterna, professora de Sociologia da Universidade de Harvard.
} 
ção e modificação do sujeito, a partir da aquisição de conhecimento e da aquisição de uma reflexão desconstrutiva, lógica, filosófica e crítica. Não percamos isso, de vista, nunca: mesmo que a Biologia "explique" certo comportamento, até certo ponto, o que nos interessa é aquilo que, no sujeito, na pessoa, no contexto individual ou coletivo, pode ser repensado e modificado pelo processo educacional. O que está ao nosso alcance (como educadoras/es) é o conjunto de comportamentos e atitudes explicados e aprendidos pelas interações da socialização, pela reflexão e apropriação de conhecimento, pelas mudanças pessoais decorrentes do livre arbítrio e das escolhas decorrentes do processo educacional. A espécie Homo sapiens sapiens pode/deve escolher por priorizar, nas relações humanas, sua evolução civilizatória e ética para o respeito, reconhecimento e bem comum (e não aspectos da sua "evolução" marcados pela selvageria ou barbárie).

Exemplo 3: Quando a metáfora do binarismo é usada como padrão de normalidade

\begin{tabular}{|c|c|}
\hline $\begin{array}{l}\text { A Biologia } \\
\text { OS FATOS BIOLÓGICOS }\end{array}$ & $\begin{array}{l}\text { Construções de Gênero } \\
\text { OS SIGNIFICADOS SOCIOCULTURAIS } \\
\text { e seus enunciados }\end{array}$ \\
\hline $\begin{array}{l}\text { 1. Na espécie humana a reprodução é se- } \\
\text { xuada (união do gameta feminino com o } \\
\text { gameta masculino). } \\
\text { 2. A reprodução é importante para a ma- } \\
\text { nutenção da espécie. }\end{array}$ & $\begin{array}{l}\text { Uma mulher deve se unir a um } \\
\text { homem. } \\
\text { A reprodução é o objetivo da união } \\
\text { de um homem e uma mulher. } \\
\text { O casal heterossexual é o natural ... } \\
\text { o normal. } \\
\text { Práticas sexuais legítimas só aquelas } \\
\text { que levam à reprodução. } \\
\text { Relacionamento entre pessoas do } \\
\text { mesmo sexo não é normal. }\end{array}$ \\
\hline
\end{tabular}

Tem sido evidente, na narrativa anti-gênero o apego ao Determinismo Biológico para enfatizar a complementaridade entre homem e mulher e, entre masculino e feminino. Tal argumento, reproduzido pela Igreja Católica (e instituições religiosas protestantes), está na base explicativa para "naturalizar" o comportamento sexual humano aceitável: a união somente entre homem e mulher, a maternidade somente no casamento, somente a família natural (que também é a família nuclear, patriarcal), a heterossexualidade como conduta compulsória. 
Luis Henrique Sacchi dos Santos (2000) afirmou, no título de seu artigo, que "a Biologia tem uma história que não é natural". Para o autor, "o conhecimento biológico é estabelecido em profundas e intrincadas redes de poder e interesse [...]" e argumenta que o conhecimento biológico assim como suas narrativas são sempre interessados (p.232) e podem ser usados para prescrição de comportamentos e para regular a vida das pessoas.

Essa deve ser a nossa preocupação como professoras/es de Biologia: identificar esses usos discriminatórios e apresentar um contraponto que promova a construção de uma sociedade de respeito e de reconhecimento das diferenças.

\section{b) Reforçando o Letramento Científico}

Os tempos atuais nos mostram que, não apenas as aulas de Ciências da Natureza e/ou Biologia, mas todos os componentes curriculares da Educação Básica precisam, dentro da epistemologia de cada Ciência, apresentar o Letramento Científico como um objetivo do ensino-aprendizado para formação de uma cidadania consciente. O negacionismo científico passa, não apenas pelo desconhecimento, mas, também, pela prioridade/relevância/importância que as pessoas conferem, em suas vidas, ao conhecimento não científico, as não ciências, as pseudociências.

Até que ponto o ensino de Ciências e de Biologia está falhando, sobretudo quando observamos tantos jovens e adultos que, sem nenhuma hesitação, acreditam em fake news, em terraplanismo, no discurso antivacinas, nas chamadas pós-verdades?

Anderson Bertoldi (2020) no seu livro "Alfabetização científica versus letramento científico" discute a distinção desses conceitos a partir de várias/os autoras/es. Para ele, a "alfabetização científica está relacionada ao processo de ensino e de aprendizagem da ciência, enquanto letramento científico seria o uso que o futuro cidadão faria desses conhecimentos" (p.10). Tal entendimento de letramento científico é corroborado por Leonir Lorenzetti e Demétrio Delizoicov em "Alfabetização Científica no contexto das Séries Iniciais": "[...] refere-se à forma como as pessoas utilizarão os conhecimentos científicos, seja no seu trabalho ou na sua vida pessoal e social, melhorando a sua vida ou auxiliando na tomada de decisões frente a um mundo em constante mudança" (Lorenzetti e Delizoicov, 2001, p. 52). 
Fica evidente as implicações políticas do letramento científico e sua relação com as mudanças sociais.

\begin{abstract}
Assim, uma educação científica fundamentada na concepção de letramento teria de explorar o ensino da metodologia da ciência e das limitações do conhecimento científico, o reconhecimento das especificidades dos gêneros textuais e do discurso desse domínio e as relações possíveis entre ciência e tecnologia e suas conexões com questões ambientais, políticas, econômicas, éticas, sociais e culturais. (BERTOLDI, 2020, p.10)
\end{abstract}

Rodrigo Bastos Cunha, em seu livro "Por que falar em Letramento Científico?" afirma que "o termo é normalmente visto como sendo sinônimo de "percepção pública da ciência" (2019, p.57). Para o autor, há "grupos de interesse" pelo letramento científico: o primeiro grupo, seria formado pela comunidade do Ensino de Ciências (professoras e professores de Ciências da Natureza e Biologia) presente no sistema educacional (p.65); o segundo grupo, por cientistas sociais e pesquisadoras/es de opinião pública preocupados com questões de política de ciência e tecnologia (p.66); o terceiro grupo, formado "por pesquisadores da sociologia da ciência e educadores científicos que empregam uma abordagem sociológica no letramento científico. Esses pesquisadores estão preocupados com a construção de responsabilidade com relação à ciência" (p.66) e o quarto grupo, comunidade de ensino de ciência não formal que promovem a divulgação ciência de várias formas (museus, jardins botânicos, zoológicos, jornais, TV, rádio, mídias em geral, etc.) (p.67).

A partir dessa classificação e, independente dela, pergunto: Quais seriam os grupos desinteressados no letramento científico? Pessoas e instituições que propagam o Projeto Escola Sem Partido? Instituições que afirmam existir uma "ideologia de gênero", que consideram mais importante, para guiar a vida das pessoas, doutrinas e éticas baseadas em religião, por exemplo? Reforço aqui, a importância das aulas de Ciências da Natureza e de Biologia: as crianças e jovens precisam se apropriar do raciocínio lógico; entender o método científico; compreender a conexão entre conhecimento, fatos e evidências; adquirir uma atitude investigativa, curiosa e desconfi- 
ada com a informação; distinguir conhecimento científico de senso comum ou crença ${ }^{4}$.

\section{c) Aproximando-se a Biologia das Ciências Humanas e Sociais}

Desde o momento em que eu, profissionalmente, assumi que seria uma educadora sexual tive uma certeza: qualquer tentativa em desenvolver um processo de ensino-aprendizado voltado ao respeito às diferenças, à superação das desigualdades de gênero, que questionasse as representações atribuídas a homens e mulheres, que buscasse ampliar o olhar humano aos significados sociais e culturais da sexualidade, por exemplo, teria, necessariamente, que começar a questionar o ponto de vista da Biologia. E mais do que isso: teria que aproximar a Biologia das reflexões advindas da filosofia, da antropologia, da história, da sociologia, da Pedagogia. Aceitei o desafio de me colocar nesse papel - o de ressignificar o campo que me formou e me constituiu, inicialmente.

Era preciso entender como a Biologia era utilizada como instrumento de limitação do olhar humano à vida sexual de homens e mulheres e como ela (a Biologia), convenientemente, estava articulada com discursos e interesses conservadores e/ou retrógrados. Para isso, ela, necessariamente, precisaria ser questionada, tanto em relação a amplitude das expressões da sexualidade não reprodutiva (da infância até a terceira idade), quanto em relação a compreensão e reconhecimento da diversidade sexual e de gênero (como positivas e desejáveis) presente no ser humano, em todos os tempos históricos e em todas as culturas ${ }^{5}$.

\section{Exercício de análise 1}

As representações nas Ciências Biológicas não estão isentas de interpretações culturais, uso de metáforas, associações e analogias de cunho social, político e ideológico. Um exemplo é observado na Coleção Sexo e Sexualidade - CSS, de livros paradidáticos (Cida Lopes, 2000). O título do livro

\footnotetext{
${ }^{4}$ Ver o artigo Gêneros e Sexualidades - problematizando a educação e os processos de produção de conhecimentos (FURLANI, 2010).

${ }^{5}$ Ver o artigo A Biologia e a Sexualidade - um olhar sob a ótica da evolução da espécie humana (FURLANI, 1996).
} 
7 é "Fecundação - o casamento perfeito entre o óvulo e o espermatozoide" que apresentará aspectos biológicos da sexualidade, como: fecundação, ovulação, polução noturna, maturidade sexual, menstruação.

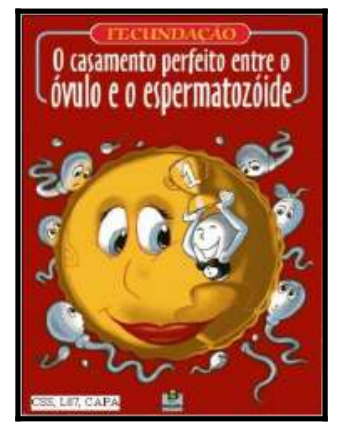

Sua capa mostra a ilustração de um óvulo que olha um espermatozoide (sptz) sorridente, levantando um troféu de $1^{\circ}$ lugar, rodeado de outros sptz, decepcionados. A abordagem pedagógica para fecundação, é meritocrática e baseia-se na representação do sptz vencedor, erguendo um troféu, sugerindo que houve uma disputa onde apenas um venceu (aquele que chegou primeiro ao óvulo) ${ }^{6}$.

Figura 01 - (LOPES, 2000, Capa do Livro 7)

Ainda que os aspectos de ordem biológica possam ser destacados (e problematizados), que aspectos culturais da representação, utilizada pelo livro, podem ser profícuos à discussão, à luz das teorias das Relações de Gênero? Maria Teresa Citeli (2004) afirmou que os gametas podem ser vistos como "fontes de metáforas de gênero", sobretudo quando observamos o caráter ativo do elemento masculino, o caráter passivo (receptor) do componente feminino (o óvulo) e a competição entre os componentes masculinos.

Pensando em relação ao conhecimento em Biologia, no que se refere ao "trabalho" dos gametas masculinos, quais os efeitos (o que ensina) essas representações: por um lado, a abordagem competitiva, individualista e vitoriosa (do sptz único) e, por outro, a abordagem solidária, coletiva e

\footnotetext{
${ }^{6}$ O Livro 08, da CSS ("Gravidez - a magia da vida") discute novamente a fecundação (p.0203). Afirma que ela é "o encontro do óvulo com o sptz". A seguir, faz a pergunta: [...] por que somente um consegue fecundar o óvulo? (CSS, L08, p.03). A CSS, ao responder a questão, vai esclarecer o processo químico que leva à degradação do óvulo (que de certa forma deixou de ser mencionado e explicado no livro anterior - 7): [...] em volta do óvulo existe uma camada que parece uma gelatina. Todo sptz leva em sua cabeça um líquido para dissolver essa camada e assim conseguir penetrar o óvulo (CSS, L08, 03). Tal informação parece que se tornaria mais apropriada e desejada, exatamente no exemplar que se propõe a discutir a fecundação (L07) e não no exemplar sobre a gravidez (L08). Mas mesmo assim, o equívoco biológico persiste sobretudo, pela ênfase que concede na representação de competição entre os gametas e da representação do sucesso pelo esforço único.
} 
igualmente vitoriosa (dos milhares de sptz que possibilitam da fecundação ocultada no livro 7)?

Parece que a representação de competição caminha no sentido a explicitar e a fortalecer a ideia de sucesso reprodutivo - um aspecto cultural também presente na construção da masculinidade. Neste sentido, a possível implicação representacional do desenho da capa e da ilustração da página 01 apontam no sentido de enaltecer o casamento institucionalizado nos moldes da heterossexualidade: o óvulo (desenhado como uma noiva) e um sptz (o noivo - vestido de fraque) sugerem, não apenas o 'casamento perfeito' mas, por conseguinte, o 'relacionamento perfeito' (a heterossexualidade).

A cena de casamento, onde os gametas estão de braços dados, apoia-se num texto que sugere o vínculo conjugal, como antecedente obrigatório para maternidade e paternidade, pretendidos pelo casal: "Para que o bebê seja formado é necessário o encontro de um espermatozoide com um óvulo" (CSS, L07, p.01). O nascimento dos filhos e filhas parece que será justificado, tanto em decorrência da união do casal (ou seja, de uma conjugalidade formal) quanto, pelos laços afetivos, estabelecidos entre

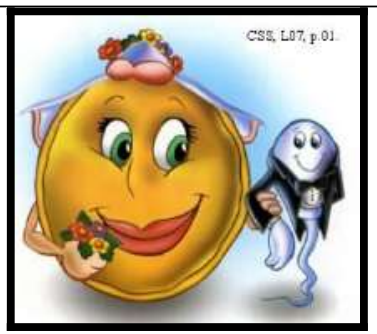

Figura 02 - (LOPES, 2000, Livro 7, p.01) eles.

A Biologia Celular, mais especificamente o processo de fecundação, foi também impactado pelos Estudos de Gênero. Os relatos que começaram a ser questionados, por estudiosas de gênero norte-americanas (como Emily Martin), na década de 1970 (mas que ainda persistem em livros de Ciências e de Biologia), afirmam, de modo irônico, que [...] "nessas sagas de concepção, o herói espermático persegue ativamente o óvulo, sobrevivendo ao ambiente hostil da vagina e derrotando inúmeros rivais" (Schiebinger, 2002, p.272). Para o ensino da Biologia e para a postura de professoras/es é importante não esquecer que "analogias e metáforas funcionam para construir, tanto, quanto para descrever - elas têm tanto uma função de criação de hipótese, como de elaboração de prova (Schiebinger, 2002, p.275).

A reflexão da nossa prática docente, como biólogas/os, exige, portanto, que reflitamos, sempre, a partir do questionamento: que efeitos, essa representação da Biologia, exerce sobre as pessoas? Que condutas sociais e "verdades" sobre homens e mulheres essa representação biológica, 
promove? Em que medida, essa representação da Biologia, reforça certos comportamentos e certos preconceitos?

Nesse exercício de análise, poderíamos ainda perguntar: Que outras formas de relacionamentos estariam excluídas dessa representação que, além de estabelecer uma fórmula de casamento "perfeito" a vincula, como antecedente tácito, à maternidade/paternidade? Que outros exemplos, como este, de determinismo biológico, estão presentes nas aulas de Biologia, nos materiais didáticos e na reiteração da prática pedagógica de professoras e professores?

\section{Exercício de análise 2}

Buscando ilustrar o caráter paradoxal da Biologia e, a importância que ela assume em se aproximar dos Estudos das Relações de Gênero, trago a análise da representação presente em livro didático, acerca da evolução da espécie humana, para reflexão. O olhar de gênero torna-se necessário sobre o modelo e norma gramatical genérica de escrita no masculino, a partir da seguinte afirmação, do livro de Fernando Gewandsznajder (2006): "Homo habilis: viveu entre 2 e 3 milhões de anos atrás e já fabricava uma espécie de 'faca de pedra' lascada; era mais alto que o australopiteco e tinha cérebro maior que o dele".

A escrita e a linguagem são locais de sexismo. Os Estudos das Relações de Gênero, sobretudo, aqueles baseados na perspectiva pós-estruturalista, reconhecem a importância da escrita, tanto para dar visibilidade às mulheres (no transcorrer da história, como sujeitos protagonistas), quanto para que a ciência que descreve o fato, não cometa equívocos e imprecisões quanto a informação que transmite.

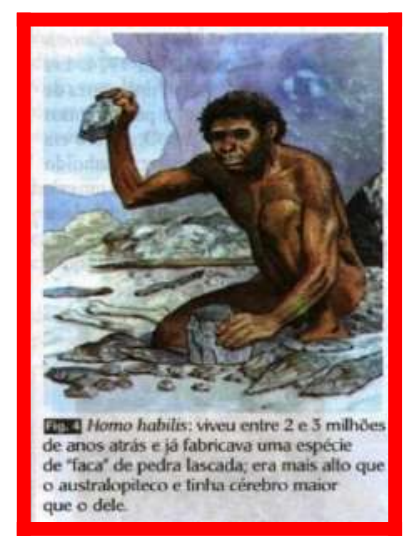

Fonte: GEWANDSZNAJDER, 2006. 
O modo como o livro didático apresenta a ilustração e o texto, com ênfase na linguagem masculina, pode sugerir que, apenas os machos da espécie Homo habilis tenham participado da criação de utensílios e artefatos, ao longo da evolução humana. Tais argumentos tomam sentido diante da reflexão do paleontólogo Timothy Taylor (1997):

\begin{abstract}
Geralmente, considera-se que os primeiros utensílios de pedra tenham sido confeccionados por caçadores. Podem ter sido, mas uma série de indícios relacionados ao sexo, tamanho do cérebro e mudanças nos mecanismos de parto corroboram a ideia de que foram as mulheres que lideraram o caminho na criação de uma cultura distintamente humana" (TAYLOR, 1997, p.06) (grifos meus).
\end{abstract}

Taylor (1997) estava se referindo a "fêmea da espécie", naquele momento do desenvolvimento evolutivo humano, que, devido a vários aspectos da sua biologia, exerceu funções sociais que lhe permitiu inventar artefatos (p.ex. a faca de pedra lascada) e promover o desenvolvimento de uma cultura humana. No entanto, a forma de linguagem do livro didático (generalizada no modo masculino de linguagem), tacitamente, visibilizava as mulheres do protagonismo histórico (assim como faz com pessoas negras, pessoas indígenas, com quilombolas etc.). Que outras situações, a linguagem genérica no masculino, torna invisível protagonistas da história?

É exatamente a partir do ponto de vista da ocultação do sujeito histórico, da imprecisão na descrição do fato constatado (descrito na imagem, no texto do livro didático) e do sexismo presente na linguagem, que as Ciências Biológicas pode ter como aliado, o olhar das Ciências Humanas e Sociais, especialmente, para quem pretende ensinar Biologia. O referencial teórico pós-estruturalista compreende a importância da linguagem, tanto na construção das identidades dos sujeitos, quanto na apropriação e uso das Ciências nos processos que hierarquizam sujeitos, acentuam desigualdades sociais e reforçam preconceitos.

\title{
Exercício de análise 3
}

As aulas de Ciências da Natureza (06 a 14 anos - Ensino Fundamental) quanto, de Biologia (14 a 18 anos - Ensino Médio) sempre estiveram na "linha de frente" da discussão da Educação Sexual (mesmo sem a intencionalidade, inicial, das/os professoras/es ou mesmo sem a presença curricu- 
lar, explícita). São nas aulas de Ciências e/ou de Biologia que as crianças e jovens expressam seu interesse pelo tema, "se sentem mais à vontade para fazer perguntas" (Debra Haffner, 2005) e nos mostram como suas identidades se expressam no espaço escolar ${ }^{7}$.

Temas relacionados à Biologia estão sempre presentes nas dúvidas e questionamentos de púberes e adolescentes. Em pesquisa, realizada com meninos e jovens entre 12 e 18 anos $^{8}$, ao serem estimulados a elaborar perguntas de interesse, apontaram os seguintes temas (na ordem de importância): 1. gravidez, 2. ciclo menstrual, 3. sintomas da TPM, 4. pílula do dia seguinte, 5. aspecto e crescimento do pênis, 6. masturbação, 7. esporte e masturbação, 8. esporte e prática sexual, 9. "ejaculação rápida", 10. camisinha, 11. desempenho sexual, 12. sexo oral, 13. sexo anal, 14. HIV/AIDS.

É evidente a preponderância das Ciências Biológicas, como campo do conhecimento, presente nesse trabalho de Educação Sexual e na formação que requer, a quem pretenda fazer a discussão. Contudo, apenas o conhecimento científico em Biologia não seria (e não foi) suficiente para as reflexões que aqueles jovens necessitavam para assumir um comportamento responsável frente a sua sexualidade. É curioso observar que suas principais/primeiras preocupações foram, exatamente, sobre temas "relacionados" às meninas/mulheres: 1. gravidez, 2. ciclo menstrual, 3. sintomas da TPM, 4. pílula do dia seguinte. Essa constatação revelou, na postura dos meninos, dois aspectos da análise de gênero: 1ㅇ. a busca de um conhecimento que os possibilitassem transferir a responsabilidade com a gravidez, para suas namoradas/companheiras; e 2‥ Em vez de priorizar a prevenção, os jovens preferiam lidar com as consequências do "descuido" (utilizar a pílula do dia seguinte). Observe que a camisinha aparece como décimo tema de interesse e, HIV/AIDS, é o último tema.

\footnotetext{
${ }^{7}$ Em Furlani (2011, p.65), expresso a similaridade da Educação Sexual, por mim teorizada, com o entendimento de Debra Haffner (2005) sobre Crianças Sexualmente Saudáveis: 1. São aquelas que se sentem bem com seus corpos; 2 . Que respeitam os membros da família e outras crianças; 3. Que entendem o conceito de privacidade; 4. Que tomam decisões adequadas à sua idade; 5 . Que ficam à vontade para fazer perguntas e, 6. Que se sentem preparadas para a puberdade.

${ }^{8}$ Esses temas são originários de dois Projeto de Pesquisa sobre recursos didático-metodoló gicos ao trabalho de Educação Sexual com Adolescentes: o primeiro projeto, realizado em abril de 2008, com meninos/jovens da Categoria de Base do Avaí Futebol Clube, dentro do Projeto Educação para a nossa Sociedade; o segundo, realizado em julho de 2012, com meninos/jovens da Categoria de Base do Figueirense Futebol Clube, dentro do Programa Jovem Furacão.
} 
Ficou, portanto, evidente, nessa formação com meninos e jovens que, apenas o conhecimento em Biologia não seria capaz de promover uma Educação Sexual de responsabilidade, que levasse a mudança de comportamento (de não transferência, mas de controle da sua própria vida) e o assu mir de uma atitude de prevenção frente a gravidez e DSts/HIV/AIDs. Os Estudos das Relações de Gênero (com suas reflexões no campo da filosofia/ ética, da sociologia, da antropologia) foram fundamentais para que esses jovens entendessem significados diversos, como: o exercício de uma sexualidade responsável, a maternidade/paternidade como um projeto de vida (planejado e compartilhado), as relações de poder envolvidas numa relação entre duas pessoas, no controle da carreira profissional, na tomada de decisões adequadas para sua idade, etc. ${ }^{9}$.

\section{Concluindo...}

Em qualquer nível da escolarização brasileira, onde ocorra a Educação Sexual, ela não deve ser vista como "terapia grupal" (ou seja, a Educação Sexual que proponho não visa expor a privacidade de cada pessoa). A Educação Sexual não é espaço para dar conselhos pessoais: ela deve discutir temas, apresentando seu processo de construção conceitual e seus contextos de produção (o contexto histórico, o cultural, o social, o político e o discursivo). Assim como, apresentar como cada ciência (e/ou campo do conhecimento humano) discute e utiliza conceitos para seu entendimento.

Educação Sexual não é o lugar de dizer o que é certo ou errado. Entretanto, concordo com o entendimento de Debra Haffenr (2005) que "crianças/jovens sexualmente saudáveis" são aquelas/es que "tomam decisões adequadas a sua idade" e, para isso, é preciso que a Educação Sexual apresente e problematize os comportamentos e atitudes que podem ser considerados mais adequados para o exercício de uma vida sexual e afetiva, com responsabilidades. A lógica pedagógica, argumentativa e formadora, dessa Educação Sexual, deve sempre ser explicitada e: 1 . Considerar as pesquisas e o conhecimento científico produzido pela humanidade, no campo das

\footnotetext{
${ }^{9}$ Um dos motivos pelos quais o convite me foi feito para realizar a atividade de Educação Sexual, pelas instâncias promotoras, nos dois Clubes de Futebol de Florianópolis (no Avaí - a Associação de Sócios Torcedores do Avaí - ASSTA e, no Figueirense - o Projeto Jovem Furacão) foi a necessidade da prevenção, em especial da gravidez. Havia o temor que jovensatletas promissores, tivessem que interromper o processo de formação nas categorias de base, para assumir a paternidade e um casamento precoces, por exigência das famílias.
} 
Ciências Biológicas, em diálogo com as Ciências Humanas e Sociais; 2. Buscar um currículo inclusivo (que reconheça e respeite as diferenças sexuais, de gênero, étnico-racial e religiosas - entre outras identidades) articuladas a um modelo civilizatório de sociedade (que reconhece a humanidade como plural e diversa); 3 . Entender educação integral como aquela que considera a sexualidade ao longo da vida e, portanto, diferenciada conforme a faixaetária; 4. Expressar uma vontade política de superação dos preconceitos e formas de discriminação baseados nas identidades culturais dos sujeitos, buscando minimizar o sexismo, o machismo, a homofobia, a transfobia, o racismo e a xenofobia.

Quando aqui, eu menciono a Educação Integral como um ideal pedagógico e formativo, é porque entendo, a Educação Sexual, como parte integrante desse processo - a dimensão sexual deve ser vista como uma dimensão humana. A Educação Sexual está inserida na Educação Integral, assim como outras modalidades o são: a Educação para o Meio Ambiente, a Educação para o Trânsito Seguro e defensivo, a Educação Alimentar, a Educação contra as Drogas, a Educação para Cidadania, a Educação Inclusiva, a Educação Financeira, etc.). Esses temas não são disciplinas regulares (componentes curriculares), mas sim assuntos/temáticas que devem/podem ser transversalizadas no currículo ${ }^{10}$. Todos esses temas podem ser desenvolvidos nos espaços educativos da Educação Básica e devem/podem ser inseridos no Projeto Político Pedagógico, da Unidade Escolar. Da mesma forma, como outra possibilidade, a Educação Sexual pode fazer parte do trabalho pedagógico das/os profissionais da Pedagogia (Orientadora/or Educacional e/ou Supervisora/or Escolar) que muitas vezes, promovem e auxiliam no planejamento de Projetos Interdisciplinares, permanentes ou eventuais, na Escola.

Nos dias de hoje, percebemos como desqualificar a Educação Sexual tem sido uma estratégia de instituições, pessoas e grupos conservadores/reacionários. O curioso é que, o modo como usam a educação sexual, ou melhor, como a combatem, dá a impressão, para muitas pessoas, que ela "existe" nos currículos na escola. A educação Sexual nunca foi disciplina regular e, mesmo como recomendação nos PCNs

\footnotetext{
${ }^{10}$ Esse modelo educacional, que considera a transversalidade como possível, já foi apresentado na história da Educação Brasileira recente, conforme o paradigma educacional presente nos PCNs - Parâmetros Curriculares Nacionais (de 1997 a 2018). A BNCC (Base Nacional Cur ricular Comum), aprovada em 2018, após as mudanças realizadas no Congresso Nacional e $\mathrm{MEC}$, não considera a Educação Sexual tema relevante
} 
de 1997, nunca foi um tema discutido na escola, ou integrante da educação de crianças e jovens, de modo que pudesse ser considerado significativo. Em Furlani (2011, p.131) menciono a reportagem intitulada "Educação Sexual atinge somente 5,5\% das escolas", de Cássia Gisele Ribeiro (2006).

Segundo a autora, o Censo Escolar/MEC apontava que as dificuldades para tratar o tema na escola encontravam três obstáculos: o despreparo dos professores, o medo dos pais e mães e a existência de uma cultura sexista (na escola e na sociedade). Duas outras informações, importantíssimas, acompanhavam o conteúdo da reportagem: 1ạ. Educação Sexual era sinônimo de "trabalhar, semanalmente, o tema Aids e doenças sexualmente transmissíveis (DSTs)" - o que reitera a afirmação apresentada por Furlani (2011) que a Abordagem Biológica-Higienista é a que prevalece na escolarização formal ${ }^{11}$; e a 2a. informação: quando existe algum conteúdo sobre Educação Sexual "ele não é aprofundado de forma que consiga transformar comportamentos" (Ribeiro, 2006).

A mudança de comportamento tão desejada passa, também, pelo momento em que tal conhecimento é transmitido, ou seja, em que fase da vida. Nesse sentido, me parece muito mais eficiente que a educação sexual invista, primeiro, suas tentativas de formação à uma educação preventiva, na infância.

Não seria surpresa se concluíssemos que "a informação não muda comportamento" porque ela chega tarde demais: na adolescência geralmente nos trabalhos escolares realizados, nos últimos anos do Ensino Fundamental ou no Ensino Médio.

Entendo que discussões na educação sexual não devem ser apenas biológicas. Os ESTUDOS de GÊNERO têm sido fundamentais para a mudança comportamental [...] (FURLANI, 2011, p.132)

A Ciência Biológica ocupa um local privilegiado de discussão da Educação Sexual na escola, nas aulas de Ciências e Biologia. Além disso, é um campo científico respeitado e crucial para a vida em sociedade (vide a pandemia do Corona Vírus, em 2020). No entanto, é exatamente a Biologia que

\footnotetext{
${ }^{11}$ Ver em FURLANI (2011, p.15) as oito 1.1. a abordagem biológico-higienista; 1.2. a abordagem moral-tradicionalista; 1.3. a abordagem terapêutica; 1.4. a abordagem religioso-radical; 1.5. a abordagem dos direitos humanos; 1.6. a abordagem dos direitos sexuais; 1.7. a abordagem emancipatória; 1.8. a abordagem queer.
} 
tem sido utilizada/apropriada por instituições e pessoas conservadoras/retrógradas para legitimar preconceitos, difundir um discurso antigênero e retroceder a conquistas de direitos à população $\operatorname{TLGB}^{12}$. Nosso posicionamento como biólogas/os e professoras/es é importantíssimo, deve ser consciente e de defesa de uma sociedade plural.

\section{Referências}

BERTOLDI, Anderson. Alfabetização científica versus letramento científico: um problema de denominação ou uma diferença conceitual? Revista Brasileira de Educação. vol.25, Rio de Janeiro 2020 Epub Sep 07, 2020. Disponível em: https://www.scielo.br/pdf/rbedu/v25/1809-449X-rbedu-25e250036.pdf Acesso em: 28 out 2020.

CUNHA, Rodrigo Bastos. Por que falar em Letramento Científico? Raízes do conceito nos estudos da linguagem. 1ạ. Ed. Campinas/ São Paulo: Estante Labjor/Nudecri/Unicampi, 2019.

FURLANI, Jimena. A Biologia e a Sexualidade - Uma discussão sob a ótica da Evolução da Espécie Humana. IN: Universidade \& Desenvolvimento. Florianópolis: UDESC, Caderno 4. Centro de Ciências Humanas e da Educação. v.3, n.1, abril 1996. Pp 38-72.

FURLANI, Jimena. Gêneros e Sexualidades - problematizando a educação e os processos de produção de conhecimento. Instrumento (Juiz de Fora), v.12, 2010. p. 45-56.

FURLANI, Jimena. Educação sexual na Sala de Aula - Relações de Gênero, orientação sexual e igualdade étnico-racial uma proposta de respeito às diferenças. Belo Horizonte: Autêntica, 2011.

\footnotetext{
${ }^{12}$ [...] nos últimos anos, tenho usado TLGB em minhas aulas, cursos e reflexões. Os níveis que a transfobia tem apresentado, sobretudo em nosso país, precisam ser combatidos. Usar TLGB é uma forma de eu dar ênfase a necessária mudança do quadro de violência que sofre a população trans. (FURLANI, 2020) Tal decisão oficial, de mudança da sigla, cabe ao movimento LGBT.
} 
FURLANI, Jimena. A narrativa "Ideologia de Gênero": impactos na Educação Brasileira e nas políticas de identidade. Porto Alegre: Mediação. 2020. (no prelo)

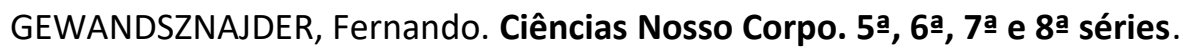
São Paulo: Ed. Ática, 2006.

HAFFNER, Debra W. A criança e a Educação Sexual. Lisboa/Portugal: Presença, 2005.

LORENZETTI, Leonir; DELIZOICOV, Demétrio. Alfabetização Científica no contexto das Séries Iniciais. Ensaio - Pesquisa em Educação em Ciências, Belo Horizonte, v. 3, n. 1, p. 45-61, jun. 2001. Disponível em: https:// www.scielo.br/pdf/epec/v3n1/1983- 2117-epec-3-01-00045.pdf. Acesso em: 28 out. 2020.

RIBEIRO, Cássia Gisele. EDUCAÇÃo SEXUAL atinge somente 5,5\% das escolas. Disponível em: http://aprendiz.uol.com.br. Acesso em: 18 outubro 2006.

RODRIGUEZ, Margarita, Por que os homens são responsáveis por $95 \%$ dos homicídios no mundo? BBC News - Brasil. Disponível em: https:// www.bbc.com/portuguese/internacional-37730441 Acesso em: 03 setembro 2020.

SANTOS, Luís Henrique Sacchi dos. A biologia tem uma história que não é natural. IN: COSTA, Marisa Vorraber (org.) Estudos Culturais em Educação. Porto Alegre: Ed. Universidade, 2000.

SCHIENBINGER, Londa. O Feminismo mudou a ciência? Bauru, SP: EDUSC, 2001.

TAYLOR, Timothy. A pré-história do sexo: Quatro milhões de anos de cultura sexual. Rio de Janeiro: Editora Campus, 1997. 